\title{
Development of the Bereavement Risk Inventory and Screening Questionnaire (BRISQ): Item generation and expert panel feedback
}

KAILEY ROBERTS, M.A., ${ }^{1,2}$ JIMMIE HOLLAND, M.D., ${ }^{1,3}$ HOLLY G. PRIGERSON, PH.D., ${ }^{3}$ CORINNE SWEENEY, PH.D., ${ }^{1}$ GEOFFREY CORNER, B.S., ${ }^{4}$ WILLIAM BREITBART, M.D., ${ }^{1,3}$ AND WENDY G. LICHTENTHAL, PH.D. ${ }^{1,3}$

${ }^{1}$ Department of Psychiatry and Behavioral Sciences, Memorial Sloan Kettering Cancer Center, New York, New York ${ }^{2}$ Department of Clinical Psychology, The New School for Social Research, New York, New York

${ }^{3}$ Department of Sociology in Medicine and Weill Department of Medicine, Weill Cornell Medical College, New York, New York

${ }^{4}$ Department of Psychology, University of Southern California, Los Angeles, California

(RECEIVEd May 23, 2016; AcCePted July 13, 2016)

\begin{abstract}
Objective: Following the loss of a loved one to cancer, a significant subset of bereaved family members are at heightened risk for mental and physical health problems; however, these family members often "fall through the cracks" of the healthcare system. A brief, clinically useful self-report bereavement risk-screening tool could facilitate more effective identification of family members in need of psychosocial support before and after a cancer loss. Thus, the purpose of this study was to develop and refine the Bereavement Risk Inventory and Screening Questionnaire (BRISQ), a self-report bereavement screening tool, and to assess its utility using feedback from bereavement experts.

Method: Quantitative and qualitative feedback from a panel of 15 clinical and research experts in bereavement was obtained through an online survey to identify the most clinically useful items and understand expert opinion on bereavement screening.

Results: The qualitative and quantitative feedback were synthesized, resulting in a $22 \%$ reduction of the item pool. While there was a general consensus between experts on the most clinically useful risk factors for bereavement-related mental health challenges and on the utility of screening, they also offered feedback on language and formatting that guided substantial revisions to the BRISQ.

Significance of results: These findings were utilized to refine the BRISQ in preparation for a second study to obtain family member feedback on the measure. By incorporating both expert and family member feedback, the intention is to create a screening tool that represents top clinical and research knowledge in bereavement in a way that effectively addresses barriers to care.
\end{abstract}

KEYWORDS: Bereavement, Grief, High risk, Screening, Family-centered care

\section{INTRODUCTION}

Attention to end-of-life care for both patients diagnosed with cancer and their families has gained an increasingly important place in medical care policy

Address correspondence and reprint requests to: Kailey E. Roberts, Department of Psychiatry and Behavioral Sciences, Memorial Sloan Kettering Cancer Center, 641 Lexington Avenue, New York, New York 10022. E-mail: Robertk1@mskcc.org. recommendations (Qaseem et al., 2008; Institute of Medicine, 2014). Yet, addressing the psychosocial needs and potential mental health struggles of family members at the end of life and throughout bereavement can prove challenging. For example, psychosocial resources for family members may be limited, and follow-up may be offered inconsistently (Downar et al., 2014; Prigerson \& Jacobs, 2001). A brief, clinically useful risk self-report assessment 
tool would enable clinicians from a variety of disciplines to better identify individuals at risk and not at risk for challenges in bereavement in order to facilitate access to psychosocial support.

The present study was the first in a three-phase project to address this need by developing a clinically useful self-report risk-screening tool-the Bereavement Risk Inventory and Screening Questionnaire (BRISQ) - to identify high-risk family members before or after losing a loved one to cancer. Using patient-reported outcome (PRO) methods, this first phase involved item generation, the second will involve item improvement through cognitive interviews with family members, and the third will involve clinical validation of the tool (Rothrock, 2011).

While the intensity of psychological symptoms tends to decrease over time in bereavement (Bonanno \& Kaltman, 2001), a relatively small but important subset of bereaved family members (Lannen et al., 2008) go on to develop more severe and persistent bereavement-related mental health challenges (Kersting et al., 2011; Kristensen et al., 2014; Prigerson et al., 2009; Aoun et al., 2015), including major depressive disorder, posttraumatic stress disorder (PTSD), prolonged grief disorder (PGD), and substance abuse. Screening for risk factors may not only provide an opportunity for prophylactic mental health support but also for prevention of the numerous emotional and physical health challenges associated with the intense and impairing psychological distress in bereaved individuals, including psychiatric hospitalization ( $\mathrm{Li}$ et al., 2005), suicidality (Latham \& Prigerson, 2004), increased rates of cancer, heart problems, gastrointestinal problems, sleep disturbances, unhealthy behaviors (Prigerson et al., 1997; Stroebe et al., 2007; Ott, 2003), stress-related physiological vulnerabilities (Kiecolt-Glaser et al., 2003), and even mortality (Schulz \& Beach, 1999; Cohen-Mansfield et al., 2013).

\section{RISK FACTORS}

Literature reviews (Burke \& Neimeyer, 2012; Lobb et al., 2010) have identified a number of risk factors associated with mental health challenges. These are captured by three main categories: background, illness/death-related, and bereavement-related factors (Burke \& Neimeyer, 2012). We further describe these categories and the supporting literature herein.

\section{Background Risk Factors}

Background risk factors for bereavement-related mental health challenges are varied and include such demographic factors as younger age (Tomarken et al., 2008), female gender (Stroebe et al., 2001;
Chiu et al., 2010), minority race or ethnicity (Goldsmith et al., 2008; Youngblut et al., 2013), and lower socioeconomic status (van der Houwen et al., 2010). Additionally, prior loss or trauma experiences and/or a previous psychiatric diagnosis can put individuals at risk when they face bereavement (Kelly et al., 1999; Ellifritt et al., 2003). Studies also suggest that an avoidant or a ruminative style of coping (Galatzer-Levy \& Bonanno, 2012; Kapari et al., 2010) and insecure attachment style (Field \& Filanosky, 2010; Johnson, 2007) have been identified as risk factors. Particularly in spouses, if the relationship with the deceased was characterized by a high degree of dependency, the surviving family member may also be at higher risk (Thomas et al., 2014; Lichtenthal \& Sweeney, 2014; Johnson, 2007). Finally, kinship to the deceased has been associated with mental health challenges, with parents of young children and elderly spouses being at greatest risk (Bonanno et al., 2004; Kersting et al., 2011; van Doorn et al., 1998).

\section{Illness/Death-Related Factors}

Greater cancer severity toward the end of life (Zisook et al., 1998), challenges with advanced care directives (Kristensen et al., 2012), and poor patient quality of life at the end of life (Garrido \& Prigerson, 2014) have been linked with greater psychological distress in bereavement. Additionally, when the circumstances of a cancer death are perceived as traumatic or unexpected by family members-such as medical interventions that result in disfigurement, uncontrolled pain, seizing or bleeding at the time of death-family members are at greater risk for PTSD (Currier et al., 2006; Zisook et al., 2013; Sanderson et al., 2013). Caregivers who experience high levels of emotional distress and/or stressful events during the patient's cancer may be particularly vulnerable to intense emotional distress during bereavement (Kapari et al., 2010; Tomarken et al., 2008). Finally, lack of emotional preparedness for the death (Barry et al., 2002; Lobb et al., 2010) and low social support (Kurtz et al., 1997; Thomas et al., 2014) can place caregivers at greater risk.

\section{Bereavement-Related Factors}

While the type and circumstances of death can have a significant impact on bereavement outcomes, studies have also found that the way individuals process the death, particularly the degree to which an individual experiences feelings of regret, guilt, shame, or selfblame (Akiyama et al., 2010; Rosenzweig et al., 1997; Kelly et al., 1999), can also place them at risk. Those who significantly struggle with maintaining a sense of meaning in life or purpose and/or with 
making sense of the death may be at increased risk for mental and physical health problems (Lichtenthal et al., 2010; Neimeyer \& Sands, 2011; Lichtenthal et al., 2013).

\section{Protective Factors}

Spirituality and religion have been found to be both protective and risk factors for intense grief reactions (Bonanno et al., 2002). Insufficient and/or negative social support has been identified as a significant risk factor, while positive high-quality social support can be a significant protective factor present at any point in the bereavement process, prior to or following the death (van der Houwen et al., 2010; Ott, 2003).

\section{NEED FOR BEREAVEMENT SCREENING}

Despite the increased risk for protracted distress that bereaved family members of cancer patients may face (Vanderwerker et al., 2005; Allen et al., 2013), they also tend to underutilize mental health services (Cherlin et al., 2007; Lichtenthal et al., 2015). As they become disconnected from medical providers after the death or if the treating medical institution has limited resources to initiate and maintain bereavement care, surviving family members often "fall through the cracks" (Azoulay et al., 2005; Sealey et al., 2015b). A recent survey of intensive care unit (ICU) medical providers and family members of ICU patients post-loss revealed that $68 \%$ of family members expressed a desire for bereavement support but only $31 \%$ reported receiving professional support for emotional concerns (Downar et al., 2014). Further, more than half of family members believed that routine bereavement screening should be a standard of care, and $98 \%$ of medical providers reported that they would support and/or participate in bereavement screening. Additionally, in their interviews with palliative care providers, Sealey et al. (2015b) found that, though providers supported the idea of bereavement screening, they viewed current methods of assessing bereavement risk as insufficient and limited by staff intuition.

Despite the compelling need for a brief self-report bereavement risk-screening tool, measures to assess transdiagnostic psychosocial risk factors for the development of bereavement-related mental health challenges have a number of limitations, contributing to challenges in the implementation of systematic screening (Sealey et al., 2015a). Clinician-administered screening tools have not proved to be reliable (Rose et al., 2011; Kristjanson, 2006; Sealey et al., 2015b), and self-report bereavement risk assessments (Jordan et al., 2005; Guldin et al., 2011) have not been widely used or validated due to their burdensome length and limited clinical utility (Agnew et al., 2010). In addition, such measures have not been developed using systematically obtained expert feedback or respondent input. This step in measure development is not only quickly becoming a standard in psychometric methodology in healthcare settings (Sofaer, 2002; Ahmed et al., 2009), but it is also crucially important in the case of bereavement, as the topic is subject to controversy (Lamb et al., 2010), is emotionally provocative, and the target respondents can be considered emotionally vulnerable. Finally, though screening tools exist for bereavement-related disorders (Ito et al., 2012), their purpose is to assess for symptoms associated with a specific disorder, rather than transdiagnostic risk factors, potentially excluding family members who do not meet the criterion being assessed.

The purpose of identifying family members at risk for developing bereavement-related mental health challenges pre- or post-loss is twofold: (1) to make a connection with the at-risk family members so that they might feel more comfortable seeking assistance in the future should they need psychosocial services, and (2) to track identified at-risk family members in order to allocate limited bereavement follow-up resources. Importantly, the BRISQ may reduce the impact of informal gatekeeping and staff bias noted by Sealey et al. (2015b) as barriers to psychosocial care by offering a brief method of universal assessment of family members pre- or post-loss that is not dependent on staff recognition of clinically significant symptoms. Many cancer settings do not have the resources to provide consistent, in-depth, specialized psychosocial care to every family member. Similarly, hospitals may lack the tools to track family members once patients die (Downar et al., 2014), and when tools are available, they have not been systematically implemented, suggesting limitations to current bereavement screening practices (Sealey et al., 2015a). A brief self-report tool administered in medical care settings could be used as a basic way to initiate a conversation about psychosocial care for each family member prior to the loss in order to provide them with psychosocial treatment options and referrals before the death occurs, regardless of risk (Lichtenthal et al., 2011).

The present study represents the first steps in developing the BRISQ to assess bereaved family members and ultimately to facilitate appropriate and effective psychosocial support. To determine the clinical utility of the BRISQ, we employed qualitative and quantitative methods to seek expert (clinicians and academics specializing in bereavement) input on an initial item pool and bereavement screening overall. 


\section{METHODS}

\section{Participants}

Consistent with methods utilized in previous studies to recruit expert panels (Butler et al., 2008), our selection of experts was purposive. Several prior studies have found that 8 to 20 is an acceptable number of experts to provide valuable information in order to validate the content of a measure (Grant $\&$ Davis, 1997; Polit et al., 2007). Using personal recommendations from other experts in the field, including members of the study team (WL, HP, and JH), 20 experts in the bereavement field were invited to complete an online survey to provide quantitative and qualitative feedback on the preliminary BRISQ.

Some 15 of the 20 bereavement experts invited participated. The remaining five individuals were unresponsive to our invitation. The majority of participants identified as both a researcher and mental health clinician $(n=10)$, with the remaining five identifying as either a clinician $(n=3)$ or a researcher $(n=2)$. Of those who reported engaging in clinical work, most were psychologists $(n=9)$, and the other 4 clinicians identified as a grief counselor $(n=1)$, psychiatrists $(n=2)$, social worker $(n=1)$, or another specialty $(n=2)$. Participants had been in the bereavement field for an average of 26 years, with a range of 7 to 41 years. While the experts all identified as non-Hispanic and Caucasian, there was an approximately equal gender distribution, with 8 males and 7 females. Additionally, the expert panel represented the American $(n=11)$ and international $(n=4)$ perspectives. The average age of participants was 58 years and ranged from 36 to 75 . Participants were informed about all the components and goals of our project and were offered $\$ 50$ compensation for their time.

\section{Measures}

\section{Bereavement Risk Inventory and Screening Questionnaire (BRISQ)}

The overall design of the BRISQ was formatted to assess various timepoints and to include a multitude of risk factors. Additionally, the BRISQ was designed in checklist format, with a "yes" or "no" response for each item, making the screening tool potentially easier to understand and faster to complete and score. However, we also sought feedback to determine the best response scale. For a number of constructs (e.g., attachment style, sense of meaning), several items were proposed in order to obtain expert feedback on the most appropriate method of assessing for these factors. Finally, the BRISQ was designed to ultimately have two different versions to be admin- istered either pre- or post-loss with language appropriate to the respective timeframe.

The preliminary items for the BRISQ were developed based on a thorough review of the bereavement risk factor literature (as described above) using reviews by Lobb et al. (2010) and Burke and Neimeyer (2012) as guides. Additionally, items verified by the literature as prominent risk factors were selected from preexisting bereavement screening tools, including the Grief Evaluation Measure (Jordan et al., 2005) and those developed by Rose et al. (2011) and Guldin et al. (2011). Items were identified as being within three main categories of risk described above: "background factors," "illness/deathrelated factors," and "bereavement-related factors" (Burke \& Neimeyer, 2012; Lobb et al., 2010).

\section{Expert Survey}

Experts provided ratings and input on all candidate items compiled through an anonymous web-based survey on a secure data-collection platform (Qualtrics, 2005). The Content Validity Index (CVI), a scale utilized in medical research scale development, was employed to obtain expert input on item relevance and to establish that the BRISQ has an appropriate selection of items sufficient to measure the construct being studied (Polit et al., 2007). The CVI is a 4-point Likert-type scale $(1=$ not relevant, $4=$ highly relevant) that has been demonstrated as effective in assessing for content validity in other studies that used expert ratings (Polit et al., 2007). Relevance was considered synonymous with clinical utility in assessing expert feedback using the CVI. For certain items that could be relevant to pre- or post-loss experiences (e.g., emotional preparedness for death), experts were asked to indicate the timepoint at which the item would be appropriate to ask. Free response boxes were also included to enter any qualitative feedback experts had to offer about a given item. Finally, they were asked to indicate their overall opinion on the value of risk screening.

\section{Procedures}

A total of 65 risk factors were selected from systematic reviews of the bereavement risk literature and previous bereavement risk-screening tools for the initial item pool. These items underwent first-level refinement using the expert opinion of $\mathrm{KR}, \mathrm{WL}$, and $\mathrm{JH}$, resulting in a preliminary pool of 49 items presented in the expert survey.

Based on modified methods proposed in previous studies (Butler et al., 2008; Polit et al., 2007), quantitative (CVI) and qualitative results from the expert survey were utilized to refine the preliminary BRISQ and develop pre- and post-loss versions. The CVI 
results were analyzed using descriptive statistics to determine which items had the highest mean ratings of clinical relevance, as well as the distribution of ratings. Items were determined to have sufficient content validity by calculating interrater agreement using methods described by Polit et al. (2007) — that is, the proportion of experts that gave an item a moderate to high relevance rating ( 3 or 4 ) on the CVI. Items that fewer than $80 \%$ of the experts rated as relevant were eliminated, except in cases where the qualitative feedback suggested that the item should be retained with changes.

The qualitative feedback provided for individual items and the overall measure was coded for shared themes using a thematic analysis approach (Braun \& Clarke, 2006). Two coders (KR and CS) developed a coding system and independently coded the responses for feedback related to content, language, additions, eliminations, and utility. The coders reached consensus on the themes, and these findings were discussed by $\mathrm{WL}$ and $\mathrm{KR}$ to determine refinements to the BRISQ. In cases where expert feedback significantly differed from the evidence in the literature or suggested changing it to such a degree that it did not represent the risk factor, the item or its language was retained. These pre- and post-loss versions of the BRISQ were further reviewed by HP and WL to refine the language and ensure that all potentially significant risk factors were included following elimination of items.

\section{RESULTS}

The original item pool of the BRISQ was reduced by $22 \%$, with retained items reflecting those that at least $80 \%$ of the experts rated as quite or highly relevant. These items corresponded with the experts' qualitative feedback and those items that the primary authors (WL and KR) determined as representative of significant risk factors within the literature. In most cases, items that were rated as relevant by the least number of experts also had weak support for their unique predictive validity in the literature (e.g., female gender, level of education, and AfricanAmerican race). The expert ratings of whether the items should be asked pre-loss, post-loss, or in both timeframes was also considered for each item. When the experts indicated that an item should be used both pre- and post-loss, the language of the item was changed accordingly in each version.

The qualitative feedback provided by the experts was generally positive regarding the included items, though suggestions for changing the language of items were offered to enhance their clinical utility. These language suggestions ranged from purely grammatical to increasing the emotional or cultural sensitivity of an item. Additionally, some experts sug- gested that certain items (e.g., trauma history) should include clear indicators of the timeframe being assessed (e.g., "prior to your adulthood") or should eliminate specific descriptors (e.g., "feeling constantly angry" to "feeling angry"). Though there was a consensus on the utility of including items assessing attachment style and personality traits, the experts were conflicted on how best to assess these concepts, offering various suggestions. They proposed additional items, such as one assessing the family member's perception of the physical pain experienced by the patient.

Specific items that were eliminated based on expert relevance ratings and qualitative feedback on their clinical utility included the time since death (given its particular use in diagnosis of PGD rather than assessing for overall risk), experiencing stress during caregiving, experiencing other stressors of daily life, feeling anxious, lacking a sense of peace, and finding comfort in spirituality or religion. Experts who rated these items as irrelevant provided such reasons as the lack of specificity of an item (e.g., other stressors eliminated); the ubiquity of the experience (e.g., stress during caregiving eliminated); or overlap with another item that captured the concept better (e.g., one attachment item retained, and spirituality eliminated in favor of meaningmaking). The feedback led to a number of changes to item language, including minor rephrasing, combination of items (e.g., those assessing attachment), and clarification of key terms.

Experts also provided qualitative input on the design of the BRISQ. With regard to the response options, some experts suggested using Likert-type scales rather than the binary yes/no option. Accordingly, items were revised to be in question form, rather than statements. Four-point Likert-type scales were assigned to each item, with the response options varying based on whether the question was meant to assess frequency or degree of agreement. One important piece of feedback was to alter references to the deceased individual, originally referred to as the "loved one," to a term without emotional valence, particularly since having a conflicted relationship with the deceased tends to put one at higher risk. Thus, references to the "loved one" were changed to the more neutral "family member." Finally, all expert participants agreed that there would be value in screening, with some noting that a self-report tool would be useful for their clinical practice or institution.

Combined, these findings guided the refinement of the screening tool language, format, and content, resulting in a final set of 34 items in the pre-loss version (BRISQ-P) and 38 items in the post-loss version (BRISQ-B). Overall, most of the risk factor 
Table 1. The broader risk categories, factors assessed, and examples of items in the revised Bereavement Risk Inventory and Screening Questionnaire

\begin{tabular}{|c|c|c|}
\hline Risk category & Risk factors & Example item \\
\hline Background & $\begin{array}{l}\text { Family member age } \\
\text { Relationship to patient or deceased }\end{array}$ & $\begin{array}{l}\text { What is your relationship to your family member who } \\
\text { is ill? }\end{array}$ \\
\hline Support & $\begin{array}{l}\text { Presence of social support } \\
\text { Satisfaction with social support } \\
\text { Desire for professional support }\end{array}$ & $\begin{array}{l}\text { Overall, do you feel satisfied with the ways in which } \\
\text { others have supported you during this difficult } \\
\text { time? }\end{array}$ \\
\hline Relationship style & $\begin{array}{l}\text { Anxious personality or relational } \\
\text { style } \\
\text { Avoidant personality or relational } \\
\text { style }\end{array}$ & $\begin{array}{l}\text { In general, do you often have concerns about getting } \\
\text { too close to people or depending too much on them? }\end{array}$ \\
\hline $\begin{array}{l}\text { Prior stressors and } \\
\text { coping style }\end{array}$ & $\begin{array}{l}\text { Past difficulty coping with loss or } \\
\text { separation } \\
\text { History of mental health problems } \\
\text { Trauma history } \\
\text { a Prior suicidal ideation } \\
\text { ? Prior suicide attempt }\end{array}$ & $\begin{array}{l}\text { Prior to your adulthood, did you ever experience any } \\
\text { major challenges (e.g., loss, separation, abuse) that } \\
\text { you consider traumatic? }\end{array}$ \\
\hline $\begin{array}{l}\text { Relationship with } \\
\text { family member }\end{array}$ & $\begin{array}{l}\text { Conflictual relationship with patient } \\
\text { or deceased) } \\
\text { Dependence on patient or deceased }\end{array}$ & $\begin{array}{l}\text { Would you characterize your relationship with your } \\
\text { ill family member as difficult. challenging. or } \\
\text { conflicted? }\end{array}$ \\
\hline $\begin{array}{l}\text { Circumstances of } \\
\text { illness (or death) }\end{array}$ & $\begin{array}{l}\text { Perception that patient experiencing } \\
\text { uncontrolled pain/distress } \\
\text { (BRISQ-P) } \\
\text { - Perception of death as painful or } \\
\text { violent (BRISQ-B) } \\
\text { - Perception of illness or death as } \\
\text { traumatic } \\
\text { Emotional preparation for death } \\
\text { - Witnessing aggressive medical } \\
\text { procedures } \\
\text { - Witnessing death (BRISQ-B) } \\
\text { Satisfaction with death notification } \\
\text { (BRISQ-B) } \\
\text { - Satisfaction with quality of death } \\
\text { (BRISQ-B) }\end{array}$ & $\begin{array}{l}\text { From your perspective. has your family member been } \\
\text { experiencing uncontrolled physical pain or } \\
\text { emotional distress? }\end{array}$ \\
\hline Caregiving experiences & $\begin{array}{l}\text { Being active caregiver } \\
\text { Conflict with family members }\end{array}$ & $\begin{array}{l}\text { Have you played an active role in caring for your } \\
\text { family member? }\end{array}$ \\
\hline $\begin{array}{l}\text { Illness (or } \\
\text { bereavement) } \\
\text { experiences }\end{array}$ & $\begin{array}{l}\text { Difficulty functioning } \\
\text { Isolating self or feeling isolated } \\
\text { Experiencing flashbacks or disturbing } \\
\text { images } \\
\text { Financial problems } \\
\text { Anger about illness or death } \\
\text { Current suicidal ideation } \\
\text { Emotional numbness } \\
\text { Avoidance of reminders (BRISQ-B) } \\
\text { Feelings of guilt associated with } \\
\text { illness or death } \\
\text { Difficulty with acceptance }\end{array}$ & $\begin{array}{l}\text { Have you found it difficult to engage and function in } \\
\text { important areas in your life since your family } \\
\text { member became ill (or since the death of your } \\
\text { family member)? }\end{array}$ \\
\hline $\begin{array}{l}\text { Meaning, identity and } \\
\text { purpose }\end{array}$ & $\begin{array}{l}\text { Difficulty finding meaning in illness } \\
\text { or death } \\
\text { Disconnection from meaning or } \\
\text { purpose in life }\end{array}$ & $\begin{array}{l}\text { Do you feel you have lost your sense of meaning or } \\
\text { purpose since your family member became ill (or } \\
\text { since the death of your family member)? }\end{array}$ \\
\hline
\end{tabular}


employed to inform referrals for professional psychosocial support. In general, participating bereavement experts confirmed Sealey et al.'s (2015b) findings on the need for a clinically useful self-report bereavement screening tool and verified the utility and thoroughness of the preliminary item pool. Our results reflected a general consensus between experts on risk factors for bereavement-related mental health challenges, with the majority of the feedback suggesting modifications to the phrasing of items and the response scale.

Although the experts agreed that the proposed content was important to include, their feedback resulted in substantial revisions to the length, presentation, and language used in the BRISQ. A significant change was the adaptation from a checklist format (with items phrased as statements and responses as yes/no options) to a question format (with Likert-type scale response options). Items that were eliminated because of their lower clinical relevance ratings by the experts or qualitative feedback were noted to be inconsistently and/or not uniquely linked to bereavement-related mental health challenges in the literature. Most notably, the items on race and gender were eliminated because the evidence of risk associated with female gender or African-American race (Burke et al., 2010; Stroebe et al., 2001) did not point to these being risk factors on their own, but rather representative of the cumulation of other risk factors (e.g., lower income, lack of provider cultural competency, and systemic oppression). Because the intent of the BRISQ is to facilitate referrals for individuals in distress, the consensus among the experts and the authors was that these demographics would be insufficient indicators of risk for prolonged distress. These and others were eliminated in order to reduce the item pool and burden of completion. We focused on retaining the most potentially powerful predictors, as suggested by the literature and the experts.

The results of our study demonstrate the importance of researcher and clinician input with respect to the specifics of item development, such as language and phrasing, rather than solely relying on the research literature, as much of the revised language on the BRISQ was facilitated by the breadth and depth of the experts' knowledge. Despite this strength, the study had several limitations, most notably the lack of both racial/ethnic diversity and diversity of professional disciplines represented by the sample. This limitation is largely due to the use of a convenience sample of experts known to the authors, a method common to psychometrics but not ideal for gathering a wide range of perspectives. A related challenge is the limited utility of expert panels on the whole. Though expert feedback has been found to be useful in assessing the content validity of items (Patrick et al., 2011), care was taken to not rely solely on expert opinion to eliminate items because of the potential to miss an important predictor. The evidence for items in the literature should be considered, and items should be retained until the measure's predictive validity can be assessed in a longitudinal study.

In order to further refine the Bereavement Risk Inventory and Screening Questionnaire and improve its utility as a self-report tool, a second phase of the study is underway that involves conducting cognitive interviews with family members of cancer patients and bereaved family members to obtain information about their comprehension of and feedback on the BRISQ-P and BRISQ-B, respectively. In part due to the limitations of expert panels, this is an essential step in PRO methodology used in healthcare settings (Patrick et al., 2011). Approaching the development and validation of this screening tool using PRO methodology increases its utility and emotional sensitivity and promotes person-centered care within palliative, hospice, and bereavement care. The BRISQ will be further refined based on family member feedback, and refined versions will be used in a longitudinal study of the psychometrics to test and finalize the BRISQ. By incorporating both expert and family member feedback, the intention is to create a screening tool that represents top clinical and research knowledge in bereavement in a way that addresses barriers to care (Sealey et al., 2015b; Lichtenthal et al., 2015) and is comprehensible and sensitive to family members who may be struggling during bereavement or caregiving.

\section{DECLARATIONS}

\section{Ethics Approval}

This study was approved by the Memorial Sloan Kettering Cancer Center (MSK) Institutional Review Board on April 16, 2014. The protocol was approved as exempt research as per 45 CFR 46.101(b)(c). HIPAA authorization and informed consent were waived as per 45 CFR 164.512(i)(2)(ii) and 45 CFR 46.116(d).

\section{Competing Interests}

The authors hereby state that they have no competing interests to declare.

\section{Funding}

This research was generously supported by National Cancer Institute grants T32 CA009461 26, K07 CA172216, P30 CA008748, F31 CA192447 and by the Seth Sprague Foundation. 


\section{Statement of Authorship}

KR designed the study, conducted data collection and analysis, and drafted and edited the manuscript. $\mathrm{JH}$ assisted with screening tool item development, editing the manuscript, and final approval. HP assisted with screening tool item development, editing the manuscript, and final approval. CS assisted with data analysis, editing the manuscript, and final approval. GC assisted with data analysis, editing the manuscript, and final approval. WB assisted with editing the manuscript and final approval. WL designed the study, conducted data analysis, and assisted with drafting and editing the manuscript. All authors read and approved the final manuscript.

\section{ACKNOWLEDGMENTS}

The authors would like to thank Robert Neimeyer, Ph.D., Laurie Burke, Ph.D., Sherry Schachter, Ph.D., and Stacy Stabler, M.D. for their contributions to the project and Lisa Rubin, Ph.D., the first author's (KR) graduate school advisor at the New School for Social Research, for her invaluable mentorship. We also thank the MSK Behavioral Research Methods Core for their support.

\section{REFERENCES}

Agnew, A., Manktelow, R., Taylor, B.J., et al. (2010). Bereavement needs assessment in specialist palliative care: A review of the literature. Palliative Medicine, 24(1), 46-59. Epub ahead of print Sep 17, 2009.

Ahmed, N., Bestall, J.C., Payne, S.A., et al. (2009). The use of cognitive interviewing methodology in the design and testing of a screening tool for supportive and palliative care needs. Supportive Care in Cancer, 17, 665-673. Epub ahead of print Nov 4, 2008.

Akiyama, A., Numata, K. \& Mikami, H. (2010). Importance of end-of-life support to minimize caregiver's regret during bereavement of the elderly for better subsequent adaptation to bereavement. Archives of Gerontology and Geriatrics, 50(2), 175-178. Epub ahead of print Apr 18, 2009.

Allen, J.Y., Haley, W.E., Small, B.J., et al. (2013). Bereavement among hospice caregivers of cancer patients one year following loss: Predictors of grief, complicated grief, and symptoms of depression. Journal of Palliative Medicine, 16, 745-751. Epub ahead of print May 22.

Aoun, S., Breen, L.J., Howting, D., et al. (2015). Who needs bereavement support? A population based survey of bereavement risk and support need. PLoS One, 10(3), e0121101. doi: 10.1371/journal.pone.0121101. eCollection 2015 .

Azoulay, E., Pochard, F., Kentish-Barnes, N., et al. (2005). Risk of post-traumatic stress symptoms in family members of intensive care unit patients. American Journal of Respiratory and Critical Care Medicine, 171, 987-994. Epub ahead of print Jan 21.

Barry, L., Kasl, S. \& Prigerson, H.G. (2002). Psychiatric disorders among bereaved persons: The role of perceived circumstances of death and preparedness for death. The American Journal of Geriatric Psychiatry, 10, 447-457.
Bonanno, G.A. \& Kaltman, S. (2001). The varieties of grief experience. Clinical Psychology Review, 21, 705-734.

Bonanno, G.A., Wortman, C.B., Lehman, D.R., et al. (2002). Resilience to loss and chronic grief: A prospective study from pre-loss to 18 months post-loss. Journal of Personality and Social Psychology, 83, 1150-1164.

Bonanno, G.A., Wortman, C.B. \& Nesse, R.M. (2004). Prospective patterns of resilience and maladjustment during widowhood. Psychology and Aging, 19, 260-271.

Braun, V. \& Clarke, V. (2006). Using thematic analysis in psychology. Qualitative Research in Psychology, 3(2), 77-101.

Burke, L.A. \& Neimeyer, R.A. (eds.) (2012). Prospective risk factors for complicated grief. New York: Routledge.

Burke, L.A., Neimeyer, R.A. \& McDevitt-Murphy, M. (2010). African American homicide bereavement: Aspects of social support that predict complicated grief, PTSD, and depression. Omega, 61(1), 1-24.

Butler, S.F., Fernandez, K., Benoit, C., et al. (2008). Validation of the revised screener and opioid assessment for patients with pain. The Journal of Pain, 9, 360-372. Epub ahead of print Jan 22.

Cherlin, E.J., Barry, C.L., Prigerson, H.G., et al. (2007). Bereavement services for family caregivers: How often used, why, and why not. Journal of Palliative Medicine, $10,148-158$.

Chiu, Y.W., Huang, C., Yin, S., et al. (2010). Determinants of complicated grief in caregivers who cared for terminal cancer patients. Supportive Care in Cancer, 18(10), 1321-1327. Epub ahead of print Oct 9, 2009.

Cohen-Mansfield, J., Shmotkin, D., Malkinson, R., et al. (2013). Parental bereavement increases mortality in older persons. Psychological Trauma: Theory, Research, Practice, and Policy, 5(1), 84-92.

Currier, J.M., Holland, J.M. \& Neimeyer, R.A. (2006). Sense-making, grief, and the experience of violent loss: Toward a mediational model. Death Studies, 30(5), 403-428.

Downar, J., Barua, R. \& Sinuff, T. (2014). The desirability of an intensive care unit (ICU) clinician-led bereavement screening and support program for family members of ICU decedents (ICU Bereave). Journal of Critical Care, 29(2), e9-e16. Epub ahead of print Dec 12, 2013.

Ellifritt, J., Nelson, K.A. \& Walsh, D. (2003). Complicated bereavement: A national survey of potential risk factors. The American Journal of Hospice \& Palliative Care, 20(20), 114-120.

Field, N. \& Filanosky, C. (2010). Continuing bonds, risk factors for complicated grief and adjustment to bereavement. Death Studies, 34, 1-29.

Galatzer-Levy, I.R. \& Bonanno, G.A. (2012). Beyond normality in the study of bereavement: Heterogeneity in depression outcomes following loss in older adults. Social Science \& Medicine, 74(12), 1987-1994. Epub ahead of print Mar 20, 2012.

Garrido, M.M. \& Prigerson, H.G. (2014). The end-of-life experience: Modifiable predictors of caregivers' bereavement adjustment. Cancer, 120(6), 918-925. Epub ahead of print Dec 2, 2013.

Goldsmith, B., Morrison, R.S., Vanderwerker, L.C., et al. (2008). Elevated rates of prolonged grief disorder in African Americans. Death Studies, 32(4), 352-365.

Grant, J.S. \& Davis, L.L. (1997). Selection and use of content experts for instrument development. Research in Nursing \& Health, 20(3), 269-274.

Guldin, M.B., O'Connor, M., Sokolowski, L., et al. (2011). Identifying bereaved subjects at risk of complicated 
grief: Predictive value of questionnaire items in a cohort study. BMC Palliative Care, 10, 1-7.

Institute of Medicine (2014). Committee on Care at the End of Life, Division of Health Care Services. In Dying in America: Improving quality and honoring individual preferences near the end of life. M.J. Field \& C.K. Cassel (eds.). Washington, DC: The National Academies Press. Available from http://www.nap.edu/read/5801/ chapter/1\#ii.

Ito, M., Nakajima, S., Fujisawa, D., et al. (2012). Brief measure for screening complicated grief: Reliability and discriminant validity. PLoS One, 7(2). e31209. doi: 10.1371/ journal.pone.0031209. Epub ahead of print Feb 14.

Johnson, J.G., Zhang, B., Greer, J.A., et al. (2007). Parental control, partner dependency, and complicated grief among widowed adults in the community. The Journal of Nervous and Mental Disease, 195(1), 26-30.

Jordan, J.R., Baker, J., Matteis, M., et al. (2005). The Grief Evaluation Measure (GEM): An initial validation study. Death Studies, 29(4), 301-332.

Kapari, M., Addington, J. \& Hotopf, M. (2010). Risk factors for common mental disorder in caregiving and bereavement. Journal of Pain and Symptom Management, 40(6), 844-856. Epub ahead of print Aug 24.

Kelly, B., Edwards, P., Synott, R., et al. (1999). Predictors of bereavement outcome for family carers of cancer patients. Psycho-Oncology, 8(3), 237-249.

Kersting, A., Brahler, E., Glaesmer, H., et al. (2011). Prevalence of complicated grief in a representative population-based sample. Journal of Affective Disorders, 131(1-3), 339-343. Epub ahead of print Jan 8.

Kiecolt-Glaser, J.K., Preacher, K.J., MacCallum, R.C., et al. (2003). Chronic stress and age-related increases in the pro-inflammatory cytokine IL-6. Proceedings of the National Academy of Sciences of the United States of America, 100(15), 9090-9095.

Kristensen, T.E., Elklit, A. \& Karstoft, K. (2012). Posttraumatic stress disorder after bereavement: Early psychological sequelae of losing a close relative due to terminal cancer. Journal of Loss and Trauma, 17, $508-521$.

Kristensen, T.E., Elklit, A., Karstoft, K.I., et al. (2014). Predicting chronic posttraumatic stress disorder in bereaved relatives: A 6-month follow-up study. The American Journal of Hospice \& Palliative Care, 31(4), 396-405. Epub ahead of print May 16, 2013.

Kristjanson, L. (2006). Evaluation of the Bereavement Risk Index (BRI): A community hospice care protocol. International Journal of Palliative Nursing, 11(12), 610, 612-618.

Kurtz, M.E., Kurtz, J.C., Given, C.W., et al. (1997). Predictors of post-bereavement depressive symptomatology among family caregivers of cancer patients. Supportive Care in Cancer, 5, 53-60.

Lamb, K., Pies, R. \& Zisook, S. (2010). The bereavement exclusion for the diagnosis of major depression: To be or not to be. Psychiatry, 7(7), 19-25.

Lannen, P.K., Wolfe, J., Prigerson, H.G., et al. (2008). Unresolved grief in a national sample of bereaved parents: Impaired mental and physical health 4 to 9 years later. Journal of Clinical Oncology, 26(36), 5870-5876. Epub ahead of print Nov 24.

Latham, A.E. \& Prigerson, H.G. (2004). Suicidality and bereavement: Complicated grief as psychiatric disorder presenting greatest risk for suicidality. Suicide and LifeThreatening Behavior, 34, 350-362. Available from http:// www.ncbi.nlm.nih.gov/pmc/articles/PMC1459278/.
Li, J., Laursen, T.M., Precht, D.H., et al. (2005). Hospitalization for mental illness among parents after the death of a child. The New England Journal of Medicine, 352(12), 1190-1196.

Lichtenthal, W.G. \& Sweeney, C. (2014). Families "at risk" of complicated bereavement. In Bereavement care for families. D. Kissane (ed.), pp. 249-265. New York: Routledge.

Lichtenthal, W.G., Currier, J.M., Neimeyer, R., et al. (2010). Sense and significance: A mixed-methods examination of meaning making after the loss of one's child. Journal of Clinical Psychology, 66(7), 791-812.

Lichtenthal, W.G., Nilsson, M., Kissane, D.W., et al. (2011). Underutilization of mental health services among bereaved caregivers with prolonged grief disorder. Psychiatric Services, 62(10), 1225-1229.

Lichtenthal, W.G., Neimeyer, R.A., Currier, J.M., et al. (2013). Cause of death and the quest for meaning after the loss of a child. Death Studies, 37(4), 311-342.

Lichtenthal, W.G., Corner, G.W., Sweeney, C.R., et al. (2015). Mental health services for parents who lost a child to cancer: If we build them, will they come? Journal of Clinical Oncology, 33, 1-10. Epub ahead of print Jun 1.

Lobb, E.A., Kristjanson, L.J., Aoun, S.M., et al. (2010). Predictors of complicated grief: A systematic review of empirical studies. Death Studies, 34(8), 673-698.

Neimeyer, R.A. \& Sands, D.C. (2011). Meaning reconstruction in bereavement: From principles to practice. In Grief and bereavement in contemporary society: Bridging research and practice. R.A. Neimeyer et al. (eds.), pp. 9-22. New York: Routledge.

Ott, C.H. (2003). The impact of complicated grief on mental and physical health at various points in the bereavement. Death Studies, 27(3), 249-272.

Patrick, D.L., Burke, L.B., Gwaltney, C.J., et al. (2011). Content validity: Establishing and reporting the evidence in newly developed patient-reported outcomes (PRO) instruments for medical product evaluation. ISPOR PRO Good Research Practices Task Force report, part 2: Assessing respondent understanding. Value in Health, 14(8), 978-988. Epub ahead of print Oct 10.

Polit, D.F., Beck, C.T. \& Owen, S.V. (2007). Is the CVI an acceptable indicator of content validity? Appraisal and recommendations. Research in Nursing \& Health, 30(4), 459-467.

Prigerson, H. \& Jacobs, S.C. (2001). Perspectives on care at the close of life. Caring for bereaved patients: "All the doctors just suddenly go." The Journal of the American Medical Association, 286(11), 1369-1376.

Prigerson, H.G., Bierhals, A.J., Kasl, S.V., et al. (1997). Traumatic grief as a risk factor for mental and physical morbidity. The American Journal of Psychiatry, 154(5), 616-623.

Prigerson, H.G., Horowitz, M.J., Jacobs, S.C., et al. (2009). Prolonged grief disorder: Psychometric validation of criteria proposed for DSM-V and ICD-11. PLoS Med, 6(8), e1000121. doi: 10.1371/journal.pmed.1000121. Epub ahead of print Aug 4.

Qaseem, A., Snow, V., Shekelle, P., et al. (2008). Evidencebased interventions to improve the palliative care of pain, dyspnea, and depression at the end of life: A clinical practice guidelines from the American College of Physicians. Annals of Internal Medicine, 148(2), 141-146.

Qualtrics (2005). Qualtrics. Provo, Utah: Qualtrics.

Rose, C., Wainwright, W., Downing, M., et al. (2011). Interrater reliability of the bereavement risk assessment tool. Palliative \& Supportive Care, 9, 153-164. 
Rosenzweig, A., Prigerson, H., Miller, M., et al. (1997). Bereavement and late life depression: Grief and its complications in the elderly. Annual Review of Medicine, 48, 421-428.

Rothrock, N., Kaiser, K.A. \& Cella, D (2011). Developing a valid patient-reported outcome measure. Clinical Pharmacology and Therapeutics, 90(5), 737-742. Epub ahead of print Oct 5 .

Sanderson, C., Lobb, E.A., Mowll, J., et al. (2013). Signs of post-traumatic stress disorder in caregivers following an expected death: A qualitative study. Palliative Medicine, 27(7), 625-631. Epub ahead of print Apr 11.

Schulz, R. \& Beach, S. (1999). Caregiving as a risk factor for mortality: The caregiving health effects study. The Journal of the American Medical Association, 282(23), 2215-2219.

Sealey, M., Breen, L.J., O'Connor, M., et al. (2015a). A scoping review of bereavement risk assessment measures: Implications for palliative care. Palliative Medicine, 29(7), 577-589. Epub ahead of print Mar 24

Sealey, M., O’Connor, M., Aoun, S.M., et al. (2015b). Exploring barriers to assessment of bereavement risk in palliative care: Perspectives of key stakeholders. BMC Palliative Care, 14(49). Epub ahead of print Oct 14. Available from http://bmcpalliatcare.biomedcentral. com/articles/10.1186/s12904-015-0046-7.

Sofaer, S. (2002). Methodology matters: Qualitative research methods. International Journal for Quality in Health Care, 14(4), 329-336.

Stroebe, M., Stroebe, W. \& Schut, H. (2001). Gender differences in adjustment to bereavement: An empirical and theoretical review. Review of General Psychology, 5(1), 62-83.
Stroebe, M., Schut, H. \& Stroebe, W. (2007). Health outcomes of bereavement. Lancet, 370(9603), 1960-1973.

Thomas, K., Hudson, P., Trauer, T., et al. (2014). Risk factors for developing prolonged grief during bereavement in family carers of cancer patients in palliative care: A longitudinal study. Journal of Pain and Symptom Management, 47(3), 531-541. Epub ahead of print Aug 19, 2013.

Tomarken, A., Holland, J., Schachter, S., et al. (2008). Factors of complicated grief pre-death in caregivers of cancer patients. Psycho-Oncology, 17(2), 105-111.

van der Houwen, K., Stroebe, M., Stroebe, W., et al. (2010). Risk factors for bereavement outcome: A multivariate approach. Death Studies, 34, 195-220.

Vanderwerker, L.C., Laff, R.E., Kadan-Lottick, N.S., et al. (2005). Psychiatric disorders and mental health service use among caregivers of advanced cancer patients. Journal of Clinical Oncology, 23(28), 6899-6907. Epub ahead of print Aug 29. Available from http://www. ncbi.nlm.nih.gov/pmc/articles/PMC1459280/.

van Doorn, C., Kasl, S.V., Beery, L.C., et al. (1998). The influence of marital quality and attachment styles on traumatic grief and depressive symptoms. The Journal of Nervous and Mental Disease, 186(9), 566-573.

Youngblut, J.M., Brooten, D., Cantwell, P., et al. (2013). Parent health and functioning 13 months after infant or child NICU/PICU death. Pediatrics, 132(5), 1295-1301.

Zisook, S., Chentsova-Dutton, Y. \& Shuchter, S.R. (1998). PTSD following bereavement. Annals of Clinical Psychiatry, 10(4), 157-163.

Zisook, S., Pies, R. \& Iglewicz, A. (2013). Grief, depression and the DS-5. Journal of Psychiatric Practice, 19(5), $386-396$. 